\title{
Black Female Patients with TyPe 2 Diabetes Mellitus: KnOWledge, AtTitudes And Physical Activity
}

\begin{abstract}
The aim of this study was to obtain baseline data from female Type 2 Diabetes Mellitus (Type 2 DM) patients on their general health status, demographics, their knowledge of and attitudes towards diabetes and exercise, as well as their present physical activity levels.

The sample of convenience consisted of 93 patients between the ages of 36 and 70 years, who were attending the Mamelodi Hospital Diabetic Outpatient Clinic.

Demographic, clinical, diabetes knowledge, diabetes attitude and physical activity data were captured. Data were summarized with descriptive statistics. Pearson product-moment correlation was

VAN ROOIJEN AJ, MSc Physiotherapy (UOFS)'; RHEEDER P, M.MED (Internal Medicine) (UP)²; EALES CJ, PhD (WITS) ${ }^{3}$; BECKER P, PHD (UNISA) ${ }^{4}$

1 Department of Physiotherapy,

University of Pretoria.

2 Study leader, Clinical Epidemiology Unit,

${ }_{3}$ University of Pretoria

Co-study leader, Department of Physiotherapy Wits Medical School

4 Statistician, Medical Research Council, Pretoria employed to assess relationships and Cronbach's alpha measured reliability.

It was found that the sample had a low educational level. (84\% schooling up to St 7) Several risk factors for the control of diabetes were identified in the sample.(Class I obesity, HbAlc-levels acceptable to compromised, $75 \%$ on treatment for hypertension) They had low scores on knowledge of diabetes ( mean, $S D=4.72,2.05$ out of 15) and low levels of physical activity. (mean, $S D=2.85,2.09$ ) Patients agreed with the attitude in the scale that the health care professionals require skills to educate and counsel diabetic patients, as well as bring about behavioral changes in the patients. $(r=0.62)$ They also agreed that diabetes has a substantial psychosocial impact on their lives. $(r=0.41)$ The highest correlation between to sub-scales was between the need for special training of health care professionals who care for diabetic patients and the psychosocial impact of the disease. $(r=0.41)$ Patients should be educated about the basic physiology of diabetes, insulin action and causes of hypoglycaemia. They should also be motivated to increase physical activity on a continuous basis.

Culturally sensitive research is needed to identify health beliefs, motivation for the control of diabetes and environmental and personal barriers to exercise and physical activity in this population.
\end{abstract}

\section{KEY WORDS: TYPE 2 DIABETES MELLITUS, KNOWLEDGE, ATTITUDE, PHYSICAL ACTIVITY, EXERCISE}

\section{INIRODUCTION}

Type 2 Diabetes Mellitus (Type 2 DM) is present in the populations of almost all the countries in the world, and represents a significant disease burden in most developed countries.

Type 2 DM probably results from an interaction of genetic and environ-

\section{CORRESPONDENCE TO:}

\section{AJ Van Rooijen}

Department of Physiotherapy

University of Pretoria

P O Box 667, Pretoria 0001

Tel: (012) 354-2018

Fax: (012) 354-1226

Email: tvrooije@medic.up.ac.za mental factors. Economic and prosperity advancement lead to lifestyle changes and westernisation in developing countries. Lifestyle behaviours, which include obesity, lack of physical activity and diet influence the development of the disease (Songer, 1995). Further increases in Type 2 DM may be expected in the Third World as the economic advancement of these countries continues (Songer, 1995).

King, Aubert and Herman (1998), estimated that globally 325000 female patients in the age group 45-64 will have diabetes by 2025 . Studies in Durban, the greater Cape Town and Mangaung areas in the 1990's reported prevalence rates for Africans of between
5 and $8 \%$ (Omar et al, 1993). Type 2 DM occurs primarily in adults and the diagnosis is usually made after the age of 40 , although onset may occur earlier in high-risk groups (Songer, 1995). Persons with Type 2 DM can still produce insulin, but may be insulin resistant.

Risk factors for Type 2 DM include demographic and environmental characteristics such as age, obesity, physical activity, a sedentary lifestyle, dietary habits, smoking and the degree of westernisation. Type 2 DM is often characterised by late stage complications, including retinopathy, nephropathy, neuropathy and macro-vascular disease (Songer, 1995). 
Westaway and co-workers (1998) conducted a study on the health status and quality of life amongst urban black patients with Diabetes Mellitus in the Mamelodi community. They recommended a comprehensive diabetes health promotional programme that focuses on self-management by diabetics through active participation in their care. The core components of such a programme should include knowledge and understanding of diabetes, the development of skills for dietary, exercise and treatment adherence, the role of social support and the use of self-incentives for controlling diabetes.

The aim of this study was to obtain baseline data from female Type 2 DM patients on their general health status, demographics, their knowledge of and attitudes towards diabetes and exercise, as well as their present physical activity levels.

\section{METHOD}

Ethical clearance for the study was obtained from the Ethics Committee of the Pretoria Academic Hospital (Number 116/99).

The superintendent and matron of the Mamelodi Hospital also consented to the study.

\section{SUBJECTS}

The convenience sample consisted of 93 female Type $2 \mathrm{DM}$ patients between the ages of 36 and 70 years, attending the Mamelodi Hospital Diabetic Outpatient Clinic in Mamelodi. The only exclusion criterion was mental incompetence.

The research was conducted parallel to a research project on the diabetic foot by Prof P Rheeder and team members. Patients came for two visits, during which the interviews were conducted and the clinical data obtained. Patients were compensated for their transportation costs. The data capturing commenced on the 27th of March 2000 and was completed on the 31 st of July 2000. Four to six patients reported daily to the research venue at $08 \mathrm{~h} 00$ on the morning of their appointments. Each patient was welcomed, introduced to the research team members and asked which language they preferred. Informed consent was obtained from each patient after the aims, procedures and benefits of the study were explained to them. Subjects had an opportunity to ask questions before the consent form was signed, witnessed and each subject received a signed copy of her own consent form.

\section{INSTRUMENTATION}

Demographic, clinical, diabetes knowledge, diabetes attitude and physical activity data were captured.

The Diabetes Knowledge Form C (DKNC) scale was developed by Dunn and associates (1984), and has been used in the elderly from a variety of ethnic backgrounds. The scale comprises of fifteen questions sampling knowledge in five broad categories. The categories were: basic physiology of diabetes including insulin action, hypoglycaemia, food groups and substitutions, sick day management and general diabetes care. DKNC scores are expressed as raw scores out of 15 , or as percentage of correct answers, with higher scores indicating better diabetes knowledge. The internal reliability (0.76) of the DKNC is moderate and acceptable for use with Type 2 DM samples (Beeney et al, 1996). The scale was therefore regarded as valid.

The Modified Baecke questionnaire on physical activity for older adults was developed to enable discrimination between physically active and inactive elderly people living independently (Voorrips et al ,1991). It consists of scores for household and sporting activities, and other physically active leisure time activities, for example gardening. These scores, classified by an intensity code, together with data on the number of hours spent on the activity and the season of the year in which the activity was performed, resulted in a total activity score.

In a study by Voorrips et al, (1991), the subjects at the upper end of the scale with an activity score higher than 17 were labelled the physically active group. Subjects at the lower end of the scale, with an activity score under 9, were labelled the "sedentary group". (Reliability 0.89 , Relative Validity 0.72-0.78)

The Revised Diabetes Attitude Scale-III (DAS-III) was used to assess the impact of diabetes education programmes on the attitudes of patients and to explore the relationship between attitudes and behaviour (Anderson et al, 1990). It consists of 5 constructs, containing 35 Likert scale items (1, strongly agree; 2 , agree; 3 , neither agree or disagree; 4 , disagree; 5 , strongly disagree). The scale was revised in order to simplify the wording of the original items and to eliminate technical terms and the reading level was lowered from 12th to the 10th grade. It was tested on a sample of 1202 patients, consisting of $65 \%$ female patients with a mean age of 50.7 years. The reliabilities for the five sub-scales ranged from 0.61 for the seriousness of Type 2 DM ( 3 items) to 0.71 for the need for special training ( 7 items). These reliabilities of the DAS-3 sub-scales are adequate for group comparisons (Anderson et al, 1990).

All the scales were originally developed and validated in English.

A trained multilingual interviewer was asked to freely translate the questionnaires into the idiom of the community. A second trained interviewer was asked to translate the questionnaires back into English. A pilot study was conducted during which the first interviewer asked the questions, while the second interviewer also completed the questionnaires to see if the patients' answers were interpreted correctly by the interviewer. The same interviewer was used for the first 45 interviews, after which she was unavailable to continue with the work. A second trained multilingual interviewer was then used to complete the remaining 48 interviews. The patients were generally examined by a trained observer, participating in the diabetic foot project for the clinical data as follows:

Height was determined to the nearest $0.1 \mathrm{~cm}$ using a measuring stick attached to the wall. Weight was determined to the nearest $0.1 \mathrm{~kg}$ standing barefoot in light clothing on a calibrated electronic scale (Tanita (r)). Body mass index (Hartl, 1997) is defined as weight (in $\mathrm{kg}$ ) divided by the square of one's height (in $\mathrm{m}$ ) : $\mathrm{kg} / \mathrm{m} 2$. The normal value is predicted as $20-25 \mathrm{~kg} / \mathrm{m} 2$ (Reference range pre-obese: $\mathrm{BMI}=25-29.9 \mathrm{~kg} / \mathrm{m} 2$ Class I obese $=30-34.9 \mathrm{~kg} / \mathrm{m} 2$, Class Il obese $=35-39.9 \mathrm{~kg} / \mathrm{m} 2$, 
Class III obese $=40 \mathrm{~kg} / \mathrm{m} 2$ ). Blood pressure was measured using a Mercury Baumanometer according to published guidelines (Westaway et al, 1998)

(Reference values: Systolic blood pressure: optimal ( 130, acceptable 131-150, poor (150. Diastolic blood pressure: optimal ( 85 , acceptable 86-90, poor (90).

The glycocylated heamoglobulinvalues HbAlc (Beckman LX20(r) ), which give an indication of the average blood glucose concentration over a six to eight week period and is a good monitoring test, was used. In the 88 patients who returned for their second visit 85 sets of blood samples were obtained. In two cases obesity precluded the investigators from obtaining sufficient blood samples. One sample was insufficient for analysis (Reference values: $4.5 \%-6.5 \%$, acceptable ( $2 \%$ points above normal, compromised ( $2 \%$ points above normal) (Ligtenberg et al, 1997 and Greeff, 2000).

\section{Statistical Analysis}

Data were entered into a file on the Statistix -program on the computer, screened for missing values and range checked.

Data were analysed using Statistix (r), StatSoft's Statistica (r) and Stata (r) software.

Data were summarised with descriptive statistics, i.e. mean, SD, median, range, frequency and percentage. Pearson product-moment correlations were employed to assess relationships. Cronbach's alpha measured the reliability of the Revised Diabetes Attitude Scale-3 in this population. Alpha coefficients of $>0.70$ was regarded as satisfactory, based on Nunnally's (1978) recommendation. A mean score was calculated for each sub-scale for each individual. Then the sample mean was calculated of the construct averages for the 93 subjects. The sub-scale scores were inter-correlated, using Pearson product-moment correlation.

\section{RESUILTS}

The results are be presented in the following order:

Demographic, clinical, Diabetes knowledge scale, DAS-3 scale, Modified Baecke Scale and integrated results.

\section{Demographical data}

The demographics of this sample by age group, educational level, employment status and housing are provided in Table 1.

Table 1: Demographic data

\begin{tabular}{|l|l|l|l|}
\hline \multicolumn{2}{|c|}{ Demographics } & $\mathbf{n}$ & \% \\
\hline Age & $36-39$ & 2 & 2 \\
& $40-49$ & 13 & 14 \\
& $50-59$ & 28 & 30 \\
& $60-69$ & 48 & 52 \\
& 70 & 2 & 2 \\
\hline Educational level & None & 16 & 17 \\
& St 1-4 & 28 & 30 \\
& St 5-7 & 34 & 37 \\
& St 8-10 & 13 & 14 \\
& Post St 10 & 2 & 2 \\
\hline Employment status & None & 23 & 25 \\
& Part-time & 12 & 13 \\
& Full-time & 15 & 16 \\
& Pensioner & 43 & 87 \\
\hline Housing & Lives with partner & 7 & 5 \\
\hline & Lives with family & 81 & 8 \\
& Lives alone & 5 & \\
\hline
\end{tabular}

Eighty four percent of the sample group had schooling only up to St 7 . The sample consisted of $46 \%$ pensioners. The majority $(87 \%)$ of the patients lived with their families at the time of the interviews. All the subjects in the sample were black females.

\section{Clinical Data}

The number of patients, mean, standard deviation, median and range for the clinical data of the sample is presented in Table 2.

Table 2: Descriptive statistics for clinical data

\begin{tabular}{|c|c|c|c|c|c|}
\hline Variable & $\mathbf{N}$ & Mean & SD & Median & Range \\
\hline Age & 93 & 58.29 & 8.18 & 60.00 & $36-70$ \\
\hline Weight & 92 & 78.55 & 13.83 & 76.90 & $51.4-119.4$ \\
\hline Height & 92 & 156.71 & 5.74 & 156.20 & $144.5-173.3$ \\
\hline BMI & 92 & 31.96 & 5.14 & 31.51 & $20.88-45.61$ \\
\hline $\begin{array}{c}\text { Systolic BP } \\
\text { (SBP) }\end{array}$ & 93 & 149.94 & 25.59 & 147.00 & $96-205$ \\
\hline $\begin{array}{c}\text { Diastolic } \\
\text { Blood } \\
\text { Pressure } \\
\text { (DBP) }\end{array}$ & 93 & 89.09 & 11.09 & 90.00 & $60-120$ \\
\hline HbAlc\% & 85 & 9.82 & 2.23 & 9.90 & $5.3-13.9$ \\
\hline
\end{tabular}

$\mathrm{N}=$ number of patients $\mathrm{SD}=$ standard deviation

The sample can be classified as Class I obese. Mean score $=31.96$ (31.51). Mean HbAl clevels indicated that the sample group was in the acceptable to compromised category. Mean systolic and diastolic blood pressure results indicated that the patients were in the acceptable category (mean=149,94). However, for the average systolic blood pressure, $43 \%$ were classified as poor control and for the average diastolic blood pressure, 38 
Seventy five percent of the sample were on oral hypoglycaemic agents, with $21 \%$ patients using insulin for their diabetes.

Seventy six percent of the subjects were on treatment for hypertension.

\section{Diabetes Knowledge}

Each item is assigned a score of 1 for a correct response and 0 for an incorrect response. Items 1 to 12 in the questionnaire had a single correct answer. For items 13 to 15 , several answers are correct and a score of 1 was allocated if all the answers were correct. Only scores of 0 or 1 were used, partially correct answers scored 0 .

The mean (SD) total score of the Diabetes Knowledge scale for the sample group was $4.72(2.05)$ and the median was 5.00. Scores ranged form $0-11$ out of 15 . The percentage of correct answers was $31 \%$.

The distribution of the scores in the five broad categories of the questionnaire is reported in table 3 .

Table 3: Scores in five broad knowledge categories

\begin{tabular}{|c|c|c|c|c|c|c|}
\hline Category of knowledge & $\mathbf{N}$ & Mean & SD & Median & $\begin{array}{l}\text { Range } \\
\text { correct } \\
\text { answers }\end{array}$ & $\%$ \\
\hline $\begin{array}{l}\text { Basic physiology of diabetes } \\
\text { including insulin action } \\
\text { (Total category score) }\end{array}$ & 93 & 0.99 & 0.72 & 1 & $0-3$ & 18 \\
\hline $\begin{array}{l}\text { Insulin use during unusually } \\
\text { heavy exercise (ltem score) }\end{array}$ & 93 & 0.11 & 0.31 & 0 & $0-1$ & 11 \\
\hline Effect of insulin on blood sugar & 93 & 0.75 & 0.43 & 1 & $0-1$ & 31 \\
\hline $\begin{array}{l}\text { High blood or urine sugar level } \\
\text { and insulin }\end{array}$ & 93 & 0.13 & 0.34 & 0 & $0-1$ & 13 \\
\hline Hypoglycaemia & 93 & 0.96 & 0.79 & 1 & $0-3$ & 32 \\
\hline Normal range for blood glucose & 93 & 0.52 & 0.5 & 1 & $0-1$ & 52 \\
\hline $\begin{array}{l}\text { Symptoms not associated with } \\
\text { hypoglycaemia }\end{array}$ & 93 & 0.38 & 0.49 & 0 & $0-1$ & 38 \\
\hline Causes of hypoglycaemia & 93 & 0.07 & 0.25 & 0 & $0-1$ & 7 \\
\hline Food groups and substitutions & 93 & 2.09 & 0.95 & 2 & $0-4$ & 41.8 \\
\hline Food group rice & 93 & 0.75 & 0.43 & 1 & $0-1$ & 75 \\
\hline Food rich in carbohydrate & 93 & 0.73 & 0.45 & 1 & $0-1$ & 73 \\
\hline $\begin{array}{l}\text { Food group of which can eat } \\
\text { limitless amount }\end{array}$ & 93 & 0.54 & 0.5 & 1 & $0-1$ & 54 \\
\hline Food approved by the diabetic clinit: & 93 & 0 & 0 & 0 & 0 & 0 \\
\hline Special diabetic foods & 93 & 0.07 & 0.25 & 0 & $0-1$ & 7 \\
\hline Sick day management & 93 & 0.18 & 0.39 & 0 & $0-1$ & 9 \\
\hline $\begin{array}{l}\text { Ill and unable to eat } \\
\text { prescribed diet }\end{array}$ & 93 & 0.18 & 0.39 & 0 & $0-1$ & 18 \\
\hline Vomiting and diarrhoea & 93 & 00 & 0 & 0 & 0 & 0 \\
\hline General diabetes care & 93 & 0.95 & 0.67 & 1 & $0-2$ & 48 \\
\hline Preparation of food & 93 & 0.23 & 0.42 & .0 & $0-1$ & 23 \\
\hline Weight control & 93 & 0.72 & 0.45 & 1 & $0-1$ & 72 \\
\hline
\end{tabular}

A very low percentage of correct answers in the category on the basic physiology, including insulin action is seen. The sample scored higher in the category of knowledge about hypoglycaemia, but did not know the causes of hypoglycaemia. The subjects could answer the questions about basic food groups, but not the questions about special diabetic foods and food approved by the diabetes clinic. They were well informed about weight control in diabetes care, but scored low on the question about food preparation. Their knowledge about what to do when they become ill was nearly non existent.

\section{Leisure and household physical activity}

The total physical activity score resulting form the Modified Baecke Physical Activity Questionnaire ranged from 0.1 to 13.4. (Median $=2.23$ ) The mean score(SD) for the questionnaire was 2.85 (2.09).

The distribution of the total scores in household, sport and leisure time activities is reflected in Table 4.

\section{(See Table 4)}

Of the subjects, although all did do household activities, only $11 \%$ were involved in heavy household activities on a continuous basis as can be seen in table 5. Subjects mainly used public transport when going somewhere, with only $31 \%$ indicating that they walked. Only $11 \%$ of the sample indicated that they walked more than 5 stairs per day.

\section{(See Table 5)}

Only 3 subjects indicated that they were participating in a sport (two did bowling and one skipping) at the time of the interviews as can be seen from the low sport activity score in Table 4. Seventy three percent responded that they did take part in sport activities at school.

Seventy-seven percent of subjects indicated that they did leisuretime physical activities consisting of walking, gardening, needlework and light exercises and combinations there of. The leisure-time activity score was calculated as the cross product of codes for intensity, hours per week and months per year for each activity summed across all activities. The unitless intensity code is based on energy costs.

The number of patients, mean, standard deviation, median and range for the intensity of, the hours per week and months per year spend on leisure-time activities are presented in Table 6.

(See Table 6) 
Table 4: Physical activity scores (mean, median, range and standard deviation)

\begin{tabular}{|c|c|c|c|c|c|c|}
\hline Variable & $\mathbf{N}$ & $\begin{array}{c}\text { Percentage } \\
\%\end{array}$ & Mean & SD & Median & Range \\
\hline $\begin{array}{c}\text { Household } \\
\text { activities }\end{array}$ & 93 & 100 & 2.05 & 0.56 & 2.10 & $0.10-3.40$ \\
\hline $\begin{array}{c}\text { Sport } \\
\text { activities }\end{array}$ & 3 & 3 & 0.01 & 0.10 & 0.00 & $0.00-0.94$ \\
\hline $\begin{array}{c}\text { Leisure-time } \\
\text { activities }\end{array}$ & 72 & 77 & 0.79 & 1.85 & 0.03 & $0.00-10.70$ \\
\hline
\end{tabular}

Table 5: Frequency distribution of household activity scores

\begin{tabular}{|l|c|c|c|}
\hline Household actvity & $\begin{array}{c}\text { Value } \\
\text { patients }\end{array}$ & $\begin{array}{c}\text { Number of } \\
\text { of patients }\end{array}$ & $\begin{array}{c}\text { Percentage } \\
(\%)\end{array}$ \\
\hline Light housework & Never & 9 & 10 \\
(Dusting,washing & Sometimes & 15 & 16 \\
dishes,repairing clothes) & Mostly & 11 & 12 \\
& Always & 58 & 62 \\
\hline Heavy housework & Never & 48 & 51 \\
(washing floors, windows, & Sometimes & 22 & 24 \\
carrying trash bags) & Mostly & 13 & 14 \\
& Always & 10 & 11 \\
\hline Prepare warm meals & Never & 8 & 9 \\
& Sometimes & 20 & 22 \\
& Mostly & 18 & 19 \\
& Always & 47 & 50 \\
\hline Flights of stairs & Never & 58 & 62 \\
& $1-5$ stairs & 25 & 27 \\
& $6-10$ stairs & 8 & 9 \\
& +10 stairs & 2 & 2 \\
\hline Use of transport to go somewhere & Never & 1 & 1 \\
& Car & 2 & 2 \\
& Public transport & 61 & 66 \\
& Walking & 29 & 31 \\
\hline Go out shopping & Never & 76 & 82 \\
& $1 /$ week & 11 & 12 \\
& $2-4 /$ week & 3 & 3 \\
& daily & 3 & 3 \\
\hline
\end{tabular}

Table 6: Descriptive statistics for clinical data

\begin{tabular}{|c|c|c|c|c|c|}
\hline Variable & $\mathbf{N}$ & Mean & SD & Median & Range \\
\hline Intensity & 93 & 0.77 & 0.57 & 0.89 & $0-1.89$ \\
\hline $\begin{array}{c}\text { Hours per } \\
\text { week }\end{array}$ & 93 & 1.66 & 2.26 & 0.5 & $0-8.5$ \\
\hline $\begin{array}{c}\text { Months per } \\
\text { year }\end{array}$ & 93 & 0.15 & 0.32 & 0 & $0-0.92$ \\
\hline
\end{tabular}

The intensity of the leisure-time activities varied from sitting, using arm and movements to standing, walking, using body, arm and hand movements.

The subjects spend less than 3 hours per week and less than 3 months a year doing leisure-time activities.
Attitudes towards Diabetes and its treatment

The mean score for each sub-scale was calculated for the 93 patients. The items which did not contribute to the reliability of the construct as measured by Cronbach's alpha were excluded from the final analysis. Table 7 presents the descriptive statistics and Cronbach's alpha for each of the defined sub-scales after the items had been excluded.

Individuals were classified into one of two groups. If an individual's score on a given sub-scale was less than 3.00 , she was placed in the positive attitude group (Pos). If an individual's score was more or equal to 3.00 , she was placed in the negative attitude group (Neg).

(See Table 7)

The mean is equal to the sample mean of construct averages.

The reliabilities ranged from 0.41 for the psychosocial impact (5 items) to 0.62 for special training ( 4 items).

The sample mean reflects that the sample agrees with respect to sub-scale 1: the attitude that the health care professionals who care for patients with diabetes need teaching, counselling and change in behavioural skills.

They also agree with respect to subscale 4: an attitude that diabetes usually has a substantial psychosocial impact on the lives of people with Type 2 DM

The sample reacted neutrally with respect to sub-scale 2: that Type 2 DM is a serious disease. They also reacted neutrally to sub-scale 3 : the relative value of tight glucose control.

The sample disagreed with respect to sub-scale 5 , reflecting the attitude that patients should be the primary decisionmakers regarding the daily self-care of their diabetes.

Individuals who scored more or equal to 3.00 , were placed in the negative attitude group. A substantial number of the responses for certain sub-scales was a "3", indicating a neutral response. The items with the highest neutral scores were item 21 : “...Type II diabetes is a very serious disease" and item 25 : "...Type II is as serious as Type I diabetes."

The Pearson product-moment correlations for the five subscales are presented in Table 8.

(See Table 8) 
Table 7: Descriptive statistics for mean sub-scale scores of 93 individuals on the Revised DAS-3 Scale.

\begin{tabular}{|l|c|c|c|c|c|c|c|c|}
\hline Subscale & N & $\begin{array}{c}\text { No } \\
\text { Of } \\
\text { items }\end{array}$ & Mean & SD & Range & $\begin{array}{c}\text { Cronbach's } \\
\text { alpha }\end{array}$ & $\begin{array}{c}\% \\
\text { Pos }\end{array}$ & $\begin{array}{c}\% \\
\text { Neg }\end{array}$ \\
\hline Special training & 93 & 4 & 1.87 & 0.29 & $1.00-2.50$ & 0.62 & 98 & 2 \\
\hline $\begin{array}{l}\text { Seriousness of } \\
\text { TYPE 2 DM }\end{array}$ & 93 & 3 & 3.04 & 0.56 & $1.67-4.0$ & 0.58 & 24 & 76 \\
\hline $\begin{array}{l}\text { Value of tight } \\
\text { control }\end{array}$ & 93 & 3 & 2.79 & 0.49 & $1.67-3.67$ & 0.55 & 37 & 63 \\
\hline $\begin{array}{l}\text { Psychosocial } \\
\text { impact }\end{array}$ & 93 & 5 & 2.20 & 0.42 & $1.20-3.20$ & 0.41 & 67 & 33 \\
\hline \begin{tabular}{l} 
Patient autonomy \\
\hline
\end{tabular} & 93 & 4 & 3.95 & 0.42 & $3.00-4.75$ & 0.55 & 12 & 88 \\
\hline
\end{tabular}

$1=$ Strongly agree $\quad 2=$ Agree $\quad 3=$ Neutral $4=$ Disagree $5=$ Strongly disagree Pos $=$ positive $\mathrm{Neg}=$ negative

Table 8: Pearson product-moment correlations between subscales

\begin{tabular}{|l|c|c|c|c|c|c|}
\hline No & Sub-scale(SC) & SC1 & SC2 & SC3 & SC4 & SC5 \\
\hline 1 & Special training & - & & & & \\
\hline 2 & Seriousness of TYPE 2 DM & 0.29 & - & & & \\
\hline 3 & Value of tight control & 0.28 & -0.01 & - & & \\
\hline 4 & Psychosocial impact & 0.41 & 0.11 & 0.17 & - & \\
\hline 5 & Patient autonomy & 0.33 & 0.07 & -0.27 & 0.12 & - \\
\hline
\end{tabular}

No $=$ sub-scale number $S C=$ sub-scale

The highest correlation between two sub-scales was between the need for special training and the psychosocial impact of the disease $(r=0.41)$. The remaining correlations were low to moderate, indicating that the sub-scales were measuring relatively independent attitudes; however, it is recognised that the sub-scale reliabilities attenuate these correlations to some degree (Anderson et al, 1990)

\section{DISCUSSION}

In this study, baseline data were captured about the general health status, demographical profile, knowledge of and attitudes towards diabetes and exercise, as well as their present physical activity levels. The sample consisted of mainly older urban black female Type 2 DM patients in Mamelodi (mean, median $=58,60$ years). The convenience sample comprised of 93 female Type 2 DM patients in Mamelodi who voluntarily joined the Diabetes Foot project to which the current study was linked.
The sample size was too small for the use of the instruments. Nunnely (1978), stated that the sample size should have ten respondents per item in a questionnaire in order to test the reliability and validity of the instrument. However, the results can be used as a pilot study to obtain baseline data. No attempt was made to control for extraneous factors such as stress, physical illness and the use of drugs, which can affect blood glucose levels.

The design of the study was sufficient to obtain baseline data, because all the data were collected at the same time and patients were contacted only once. The study was relatively cheap and easy to carry out.

The principal findings of this study are the identification of several risk factors for the control of diabetes. The patients were mainly older and with a low educational level. Clinical data showed that they were Class I obese and that their glucose control were acceptable to compromised. Although
$75 \%$ of the sample were on hypoglycaemic agents and $21 \%$ were using insulin for their diabetes, they had little knowledge about the basic physiology of diabetes and insulin action, symptoms associated with hypoglycaemia, sick day management and preparation of food. The physical activity score showed that although $62 \%$ and $77 \%$ of the patients did household and leisure-time activities respectively, it were mainly light household tasks and that they spend less than 3 hours per week, less than 3 months a year doing leisure-time activities. The relevance of these findings was compared to other studies and will now be discussed.

The total score of the Diabetes Knowledge scale (4.7) compares favourably to the score reported by Campbell (1996). He reported total scores of 4.8 to 5.8 out of a possible total score of 15 in a sample of 229 Type 2 DM patients, whose mean age was 59 years and of whom $52 \%$ were female. However Beeney and co-workers (1996) reported a mean score of 7.6 , in a sample of 460 mostly older Type 2 DM population., which is $50 \%$ correct answers compared to the $33 \%$ of the current study.

The subjects' higher scores in the categories of knowledge about hypoglycaemia , basic food groups and weight control indicate that they had received some education, most probably at the Mamelodi Diabetes Clinic. The lack of knowledge about the basic physiology of diabetes, insulin action and causes of hypoglycaemia is an important finding, since $97 \%$ of the patients were on either oral hypoglycaemic agents, insulin or a combination. The lack of knowledge of the subjects is further emphasised by the finding that only $52 \%$ of the sample knew the acceptable HbAlc values. Beeney and co-workers (1996) stated: "Patients with previous formal diabetes education who are not treated with exogenous insulin should still understand the physiological action of endogenous insulin secretion and its role in diabetes." The low education level and the high mean age of the subjects can be considered as contributing factors to the lack of knowledge, since the ability of the elderly to learn and practise self-care, may be compromised 
by demographic and environmental factors. (Songer, 1995) Nilsson et al (1998), report that the relative mortality risk is increased in women who are less well educated, single and lacking socioeconomic resources.

In a population based study among 48315 adults with diabetes in 21 states in America, Beckles et al (1998), found that insulin use, socio-economic status (as judged by level of education), access to care and extent of continuing education (as judged by awareness of $\mathrm{HbAlc}$ ) were important factors related to diabetes management.

The measurement of knowledge remains important to diabetes management and is essential before an effective educational programme can be implemented. (Westaway et al, 1998) Every patient should be provided with full and accurate information about the underlying patho-physiology of diabetes as a rationale for its treatment. Logically it would seem that more knowledge will enable the patient to put into practice those self-care behaviours which will contribute to improvement in metabolic control. However, Tu and co-workers (1993) reported in a study on diabetes self-care knowledge, behaviours and metabolic control of older adults in a sample of 27 Type 2 DM patients, mean age of 65 , including 18 females and 13 black subjects, that focus of education for older adults with diabetes should be placed on effecting changes in selfcare behaviours. Adherence should not be measured based solely on metabolic values.

This viewpoint is shared by Lockington et al, (1988) who did a study on knowledge profile and control on 72 Type 2 DM patients, mean age 58 years. They recommended that for good blood glucose control, a minimum level of knowledge is necessary above which other factors, including attitudes, health beliefs and motivation, are likely to be of much greater importance. Anderson and co-workers (1993) in a study on 1202 subjects of whom, 769 were Type 2 DM, 64\% female, mean age 59 years, reported that patients who reported high adherence to exercise recommendations expressed lower agreement on the subscale for negative impact of diabetes. Little is known about the health beliefs and motivation related to the culture of the present sample.

The subjects scored very low on the Modified Baecke Questionnaire on Physical Activity and can be classified as having a sedentary lifestyle (Beeney \& Dunn, 1990).

The more active subjects were doing household and leisure time activities, but not on a regular basis. In a study on 255 white postmenopausal women, aged 50-65 years, Cauley and co-workers (1987), reported work, leisure and sport indices of respectively $2.7,3.1$ and 2.2. The household score of the present study compares favourably with the one reported by Cauley et al,(1987), but the leisure and sport indices of the present study are much lower than the scores reported by them. Ligtenberg et al (1997) showed a mean physical activity score of 8.7(5.2) in their study on the effects of physical training on metabolic control in 58 Dutch Type 2 DM patients with a mean age of 64 including 38 females. Unfortunately only the total questionnaire score was reported, but it is well above the total score obtained by the subjects in the present study.

A decline in physical activity is generally observed with ageing and the reduced energy expenditure, without adjusted energy intake may lead to overweight. The class I obesity status and sedentary lifestyle of this sample are risk factors for cardiovascular disease (Ligtenberg et al 1995), and they may also lead to complications such as osteo-arthritis of the weight-bearing joints (Voorrips et al, (1992). Overweight and obese people are less likely to engage in physical activity, because excess body weight may increase the difficulty of physical activity and this may lead to functional limitations (Blair et al, 1998). In a study to assess physical activity behaviour and its correlates (i.e. physical activity knowledge, barriers and outcome expectations) in 260 older adults with Type 2 DM, Hays and Clark (1999) found that individuals who were older, had ( 12 years of education and perceived their health as fair or poor were less likely to be physically active. They also showed that sociodemographic variables have an important influence on the odds of being physically active. All the above mentioned factors are present in this study, such as the mean age of the subjects, the low level of education and clinical data. The encouragement of physical activity among these patients has become an important goal of preventative medical practice. However, initiating and maintaining a physically active lifestyle is a complex health behaviour (Blair et al, 1998). Personal barriers to physical activity participation of these subjects are unknown and should be investigated.

Understanding the self-care behaviour of patients with diabetes and responding to their needs with appropriate patient education requires some knowledge of their attitudes toward the disease and diabetes care (Anderson and Fitzgerald, 1993). Patients who report high levels of adherence for diet and exercise and monitoring reported higher levels of understanding diabetes, had more positive attitudes toward diabetes and better overall health (Anderson \& Fitzgerald, 1993).

Ninety eight percent of subjects agreed that there is a need for special training of health care professionals taking care of diabetes patients. (Cronbach's alpha $=0.62, \%$ Positive answers $(\operatorname{Pos})=98)$. This finding shows that patients want special expertise from their health care professionals. The results of the present study correlate with a large study by Anderson et al, (1990) consisting of $65 \%$ female subjects with a mean age of 51 years. He reported a Cronbach alpha $=0.71$ and \% Pos $=99.7$ The sample also agreed with the attitude that diabetes has a substantial impact on their lives, which suggests that diabetes and its complications detract from the quality of life for most patients. (Cronbach's alpha $=0.41, \%$ Pos $=67 \%)$. Anderson et al, (1990) reported a Cronbach's alpha of 0.68 and 94\% positive answers. This finding supports the study by Westaway et al, (1998) that health status and quality of life are poorer for diabetic patients than for well persons in a similar sample from Mamelodi. Pearson productmoment correlation between sub-scales showed that the need for special training correlated strongly with the psychosocial impact of the disease $(r=0.41)$. 
Anderson et al, (1990) found this to be 0.35 . The neutral and negative responses to sub-scales 2, 3 and 5 are in contrast to results by Anderson, who reported positive responses to all three of the mentioned sub-scales. This finding suggests that the patients did not understand all the questions. Although the revised Diabetes Attitude Scale was rewritten to eliminate technical terms and the reading level was lowered from the 12 th to the 10th grade, it is clear that some of the concepts were unknown to the patients, for instance "tight control".

One possible explanation may be the average low educational level of the sample. Despite the fact that the second interviewer received similar training to the first interviewer, the use of two interviewers may have influenced the results. The process of translation of the measuring instruments into the idiom of the community was a limitation of this study. Although the process described by Anderson et al, (1990) was followed, the free translation of the questionnaires may have resulted in altering the meaning of certain items. It is suggested that in addition to the translation process that was followed in the present study, the translated instruments should be reviewed by diabetes educators, speaking the local languages to clarify ambiguous words or terms. The instrument should then be pilot-tested with a sample of diabetic patients, and the understanding of each item of the instrument should be discussed with those patients. This may ensure that the patient's understanding of the terms used matches the investigator's definition.

\section{CONCLUSION}

Several risk factors for the control of diabetes were identified in this sample of urban, black female patients in Mamelodi. They are older patients who have a low educational level. The patients have poor knowledge of their disease and are not physically active. Diabetes health education programmes are needed to improve the knowledge of the patients. Regular physical activity and exercise programs should be implemented, however the identification of environmental and personal barriers is a priority.
Cultural considerations should be kept in mind when planning educational interventions and clinical research. Any interventions should be tested against cultural relevance, sensitivity and imperialism. The use of appropriate and understandable language and the understanding of societal and cultural principles are paramount.

\section{REFERENCES}

Anderson RM, Donnelly MB, Dedrick RF 1990 Measuring the attitudes of patients towards diabetes and its treatment. Patient Education and Counseling 16:231:245

Anderson RM, Fitzgerald JT 1993 The relationship between diabetes-related attitudes and patients' self-reported adherence. Patient Education and Counseling 21:4l-50

Beckles GLA, Engelgau MM, Narayan KMV, Herman WH, Aubert RE, Williamson DF 1998 Population-based assessment of the level of care among adults with diabetes in the U.S. Diabetes Care 21:1432-1437

Beeney LJ, Dunn SM 1990 Knowledge improvement and metabolic control in diabetes education: approaching the limits? Patient Education and Counseling 16:23I-145

Beeney LJ, Dunn SM, Welch G 1996 Measurement of diabetes knowledge-the development of the DKN-scales, 2nd edn. pp 159-189. Harwood Academic Publishers, Amsterdam

Blair SN, Applegate WB, Dunn AL, Ettinger WH, Haskell WL, King AC, Morgan TM. Shih JH, Simons-Morton DG 1998 The Activity Counseling Trial Research Group. Medicine and Science in Sports and Exercise: 1097-1106

Campbell E 1996 Behaviour change in the prevention and treatment of Non-insulindepentent Diabetes Mellitus. In: Bradley C (ed) Handbook of Psychology and Diabetes,p 170. Harwood Academic Publishers, Amsterdam

Cauley JA, La Porte PHR, Sandler RB, Schramm MM, Kriska AM 1987 Comparison of methods to measure physical activity in postmenopausal women. American Journal of Clinical Nutrition 45:14-22

Dunn SM, Bryson JM, Hoskins PL, Alford JB, Handelsman DJ, Turtle JR 1984 Development of the Diabetes Knowledge (DKN) Scales: Forms DKNA, DKNB and DKNC. Diabetes Care 7:36-4I

Greeff OBW 2000 The management of Diabetes Mellitus. The Medicine Journal 42: 19-25
Hartl G 1997 Obesity epidemic puts millions at risk from related diseases. Press Release WHO / 46

Hays LM, Clark DO 1999 Correlates of physical activity in a sample of older adults with Type 2 Diabetes. Diabetes Care 22:706-712

King H, Aubert RE, Herman -WH 1998 Global burden of diabetes, 1995-2025: prevalence, numerical estimates and projections. Diabetes Care 25:26-35

Ligtenberg PC, Hoekstra JBL, Bol E, Zonderland ML, Erkelens DW 1997 Effects of physical training on metabolic control in elderly Type 2 Diabetes Mellitus patients. Clinical Science 93:127-135

Ligtenberg PC, Hoekstra JBL, Zonderland ML, Erkenlens DW 1995 Physical activity and Diabetes Mellitus. European Journal of Internal Medicine 6:95-108

Lockington TJ, Farrant S, Meadows KA, Dowlatshahi D, Wise PH 1988 Knowledge profile and control in diabetic patients. Diabetic Medicine 5:381-386

Nilsson PM, Johansson SE, Sundquist J 1998 Low educational status is a risk factor for mortality among diabetic people. Diabetic Medicine 15:213-219

Nunnely JC 1978 Psychometric theory, 2nd edn.pp230-245. McGraw-Hill, New York

Omar MAK, Deedat MA, Motala AA 1993 The prevalence of Diabetes Mellitus and impaired glucose tolerance in a group of urban South African blacks. South African Medical Journal 83:641-643

Songer TJ 1995 Epidemiology of Type II Diabetes. PharmacoEconomics 5 sup 1: [-1]

Tu KS, McDaniel G, Gay JT 1993 Diabetes self-care knowledge, behaviours and metabolic control of older adults - the effect of a post-educational follow-up program. Diabetes Educator 19:25-30

Voorrips LE, Meijers JHH, Sol P, Seidell JC Van Staveren WA 1992 History of body weight and physical activity of elderly women differing in current physical actvity. International Journal of Obesity 16:199-205

Voorrips LE, Ravelli PCA, Dongelmans P, Deurenberg P, Van Staveren WA 1991 A physical activity questionnaire for the elderly. Medicine and Science in Sports and Exercise 23:974-979

Westaway MS, Viljoen E, Rheeder P, Masemola T 1998 Determining health status and quality of life for Diabetes Mellitus urban black patients and well persons : a pilot study. Draft Report : 1-26 